\title{
Against the Grain
}

Volume 27 | Issue 5

Article 24

2015

Accucoms International BV Profile

Follow this and additional works at: https://docs.lib.purdue.edu/atg

Part of the Library and Information Science Commons

\section{Recommended Citation}

(2015) "Accucoms International BV Profile," Against the Grain: Vol. 27: Iss. 5, Article 24.

DOI: https://doi.org/10.7771/2380-176X.7190

This document has been made available through Purdue e-Pubs, a service of the Purdue University Libraries. Please contact epubs@purdue.edu for additional information. 
AW: Oh, I love this program - thanks for asking about it! There are now over 130 titles in our Production \& Hosting publishing program (http://www.elsevierpublishingsolutions.com/production_hosting.asp), and more information is available on the Website. In a nutshell, we partner with universities, societies, and governments who publish impactful journals in their regions with the aim of helping them grow their quality and readership to wield greater international influence. It's a great way to leverage our digital publishing expertise and resources. Publishing costs are typically covered by a sponsoring government agency or the journal owner, so the articles can be made available open access immediately upon publication. This model holds appeal worldwide but is currently most actively used in Brazil, China, and in the Middle East.

ATG: You also mentioned that it was very clear to you how CHORUS and SHARE (the publisher and library led approaches to addressing U.S. funder mandates) can work together. Can you elaborate? How do you see CHORUS/SHARE cooperation evolving?

AW: While both CHORUS and SHARE were stimulated by the policy environment that led to the creation of public access policies by U.S. federal funding agencies, both have continued to develop and evolve. CHORUS leverages existing infrastructure and investments to identify and facilitate public access to articles, ensure digital preservation, enhance discovery, and report on compliance. SHARE has developed its Notify service to inform interested stakeholders when research release events occur, including the publication

\title{
against thribineir profile Accucoms International BV
}

\author{
Nieuwe Energie, 3e Binnenvestgracht, 23R 2312 NR Leiden, The Netherlands \\ Phone: +31-88-4100-400 • Fax: +31-88-4100-401 \\ http://www.accucoms.com/
}

\begin{abstract}
AFFILIATED COMPANIES: Accucoms (US), Inc.
OFFICERS: Pinar Erzin, Founder and President.

ASSOCIATION MEMBERSHIPS: ALPSP, UKSG, and SSP.

KEY PRODUCTS AND SERVICES: Sales, marketing, and customers services.

CORE MARKETS/CLIENTELE: STM Publishers in Europe, North America, Latin America, Middle

East and North Africa, Turkey, India, South East Asia, South Korea.

NUMBER OF EMPLOYEES: 60

HISTORY AND BRIEF DESCRIPTION OF YOUR COMPANY: Incorporated in June 2004 offering telemarketing services for STM publishers. Quickly grown to offer dedicated/outsourced field sales and marketing services helping publishers maintain and grow their businesses in different markets around the world. Owned by Swets Information Services between August 2011 and September 2014. Fully independent and owned by its management since November 2014.
\end{abstract}

of articles and the dissemination of research data. And indeed they are working together and with shared partners - for example CHORUS metadata will be helpful in the SHARE notification service and will complement SHARE by providing public access to fulltext. It might be quite fun to interview the Executive Directors of both initiatives about this synergy. From where I sit, it is terrific that they are using similar standards - e.g., DOI, FundRef, Orcid.
ATG: Alicia, we know how busy you are and want to thank you for taking this time to talk to us. We're also looking forward to seeing you at the Charleston Conference where we hope to get another opportunity to get together and chat, perhaps for one of our Penthouse Suite Interviews.

AW: Looking forward to it. Thanks for the chat!

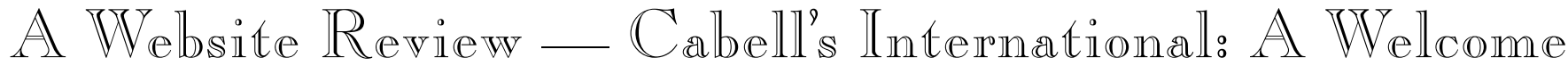
Tool in a World of Predatory Journals

by Burton Callicott (College of Charleston) <CallicottB@cofc.edu>

$\mathrm{D}$ espite a wordy alert about the use of cookies that distracts the eye, the new Cabell's International database interface is spacious and bright - you can easily click the cookie message away. Website designers at Cabell's have done their homework and utilize color, shades, intuitive tabs, and dropdowns to save space and keep things clean. At my institution, the site defaults to a basic "Journal" search. Words keyed in here result in a keyword search. Because there is little description beyond the journal supplied "Aims and Scope" or any meta-data other than the assigned discipline and topic categories, users not looking for a specific journal need to search using broad terms in order to get results. Clicking on the advanced search option greatly expands your options and allows for customized filtering: by discipline (and then by topic within discipline), difficulty of acceptance, peer review type, acceptance rate, time to review, and more.
The database is geared for three main user groups: scholars looking to identify a suitable journal for their work, librarians involved in collection development, and tenure committees looking for additional measures upon which to judge the value of a candidate's work. Scholars may initially be excited to see a special search tab entitled "Calls for Papers," but after getting little or no results here, they may abandon this tab. Searches for "algebra," "sustainability," and "ocean" resulted in zero hits. Or rather, the searches resulted in an ominous field of white where presumably there would be a list of results - it would be nice to at least get an indication that there were zero results and, even better, to get a suggestion for a different but related term that might bring up some hits. A search for "marketing" did bring up two journal titles.

A third search tab, Institutional Publishing, or IPA (Institutional Publishing Activity), is geared to appeal to

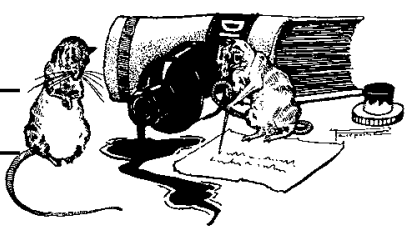

administrators - Deans, Department Heads, and even Provosts and Presidents - or scholars contemplating a move to another institution. Although I am not in a position where institutional level information would be useful, this search tab too has limited use in my opinion. If one is able to filter for a discipline and topic area that is relevant, you only get a list of institutions broken down into three somewhat elusive categories reminiscent of cup sizes at Starbucks: Premier, Significant, and High Influence. There is also another category "Accredited" where "those institutions whose faculty members publish in journals without citation counts but are accredited by national accreditation associations." Although it is possible to filter here for Humanities, you get no results. It is unclear why this is even an option since there are no humanities journals in the database. The list

continued on page 51 